\title{
Erratum to: Cost Effectiveness of Apixaban Versus Aspirin for Stroke Prevention in Patients with Non-Valvular Atrial Fibrillation in Belgium
}

Thitima Kongnakorn • Tereza Lanitis •

Lieven Annemans • Vincent Thijs - Sophie Marbaix

Published online: 10 September 2014

(C) Springer International Publishing Switzerland 2014

\section{Erratum to: Clin Drug Investig}

DOI 10.1007/s40261-014-0224-z

A published-ahead-of-print version of this article was made available online on 28 August 2014. An error has subsequently been identified in that version of the article, and the following correction should be noted:

The third author's first name was incorrectly spelt as Lievens and should appear as Lieven.

The online version of the original article can be found under doi:10.1007/s40261-014-0224-z.

T. Kongnakorn

Evidera, Bangkok, Thailand

T. Kongnakorn $(\bowtie) \cdot T$. Lanitis

Evidera, 26-28 Hammersmith Grove, London W6 7HA, UK

e-mail: Thitima.Kongnakorn@evidera.com

L. Annemans

Ghent University (Ugent), Ghent, Belgium

L. Annemans

Brussels University (VUB), Brussels, Belgium

V. Thijs

Laboratory of Neurobiology, Vesalius Research Center, VIB,

Leuven, Belgium
V. Thijs

Experimental Neurology and Leuven Research Institute for Neurodegenerative Diseases (LIND), University of Leuven (KU Leuven), Leuven, Belgium

V. Thijs

Department of Neurology, University Hospital Leuven, Leuven, Belgium

S. Marbaix

Pfizer, Brussels, Belgium 